\title{
Kernos
}

Revue internationale et pluridisciplinaire de religion grecque antique

$23 \mid 2010$

Varia

\section{Anja ULBRICH, Kypris. Heiligtümer und Kulte weiblicher Gottheiten auf Zypern in der kyproarchaischen und kyproklassischen Epoche (Königszeit)}

\section{Vinciane Pirenne-Delforge}

\section{(C) OpenEdition}

\section{Édition électronique}

URL : http://journals.openedition.org/kernos/1624

DOI : 10.4000/kernos. 1624

ISSN : 2034-7871

Éditeur

Centre international d'étude de la religion grecque antique

\section{Édition imprimée}

Date de publication : 1 janvier 2010

Pagination : 380-381

ISSN : 0776-3824

\section{Référence électronique}

Vinciane Pirenne-Delforge, «Anja uLBRIcH, Kypris. Heiligtümer und Kulte weiblicher Gottheiten auf Zypern in der kyproarchaischen und kyproklassischen Epoche (Königszeit) », Kernos [En ligne], 23 | 2010, mis en ligne le 15 septembre 2011, consulté le 21 septembre 2020. URL : http:// journals.openedition.org/kernos/1624; DOI : https://doi.org/10.4000/kernos.1624

Ce document a été généré automatiquement le 21 septembre 2020

Kernos 


\title{
Anja ULBRICH, Kypris. Heiligtümer und Kulte weiblicher Gottheiten auf Zypern in der kyproarchaischen und kyproklassischen Epoche (Königszeit)
}

\author{
Vinciane Pirenne-Delforge
}

\section{RÉFÉRENCE}

Anja ULBRICH, Kypris. Heiligtümer und Kulte weiblicher Gottheiten auf Zypern in der kyproarchaischen und kyproklassischen Epoche (Königszeit), Münster, Ugarit-Verlag, 2008. 1 vol. $22 \times 30 \mathrm{~cm}$, XII +557 p. +66 pl., 1 carte (Alter Orient und Altes Testament.

Veröffentlichungen zur Kultur und Geschichte des Alten Orients und des Alten Testaments, 44). ISBN : 978-3-934628-56-4.

1 La tradition littéraire grecque conserve l'image d'une Aphrodite omnipotente et omniprésente à Chypre. Les modernes parlent le plus souvent, à son propos, de la «Grande déesse » chypriote. À l'origine de ce livre se trouve le constat qu'une telle vision de la vie religieuse de l'île reste vraiment vague en l'absence de l'étude approfondie des quelque 200 sanctuaires qui y sont attestés. Et il faut se réjouir qu'une telle étude voit ainsi le jour car il s'agit de la somme que l'on attendait sur les cultes de Chypre. Tirée d'une thèse de doctorat présentée en 2003 à l'Université de Heidelberg, elle offre un panorama qui se veut exhaustif des données littéraires, épigraphiques, iconographiques et archéologiques dont on dispose à ce jour sur les sanctuaires chypriotes, entre 750 et 310 av. J.-C. Certes, le titre parle de divinités féminines. Toutefois, l'A. a intelligemment associé à sa réflexion les dieux mâles, et pas seulement quand ils se trouvaient en couple avec une déesse. 
2 L'A. est archéologue et l'ancrage du livre porte la marque d'une excellente connaissance du terrain. Le catalogue topographiquement structuré de tous les sanctuaires (chap. VIII) couvre la deuxième moitié de cet imposant volume et ordonne le matériau de manière systématique pour chacun des 16 lieux étudiés (dont 13, voire 15, étaient assurément des royaumes): 1) une introduction générale (histoire, économie, histoire des fouilles, attestations archéologiques, bibliographie); 2) le relevé des cultes et des sanctuaires, précédé des références aux différentes sources disponibles, dont le détail spécifique est donné sous chaque entrée. Les quelque 200 sanctuaires identifiés sont ordonnés selon une typologie territoriale fondée sur une analyse approfondie qui forme le chapitre VI et s'appuie sur les réflexions les plus récentes en terme de topographie religieuse: sanctuaires urbains, suburbains, périurbains, sanctuaires ruraux. Les chapitres I à V proposent successivement une introduction générale (I), une brève histoire de l'île et une mise au point sur les sources disponibles (II), une réflexion méthodologique sur la manière d'identifier le sexe de la divinité propriétaire d'un sanctuaire en l'absence d'identification écrite (III), une réflexion sur l'iconographie des déesses (IV), une présentation des sanctuaires identifiés par une ou des inscriptions, déesse par déesse (V). Le chapitre VII est une conclusion générale, que suit le catalogue, lui-même assorti d'une foule d'instruments de travail qui reprennent, sous forme de tableaux, le matériau du catalogue.

3 Seul un projet de thèse permet ce type d'heuristique de grande envergure et le livre conserve la trace de l'exercice qui l'a vu naître par sa rhétorique parfois un peu répétitive, mais toujours parfaitement claire. Les chapitres de synthèse, qui sont autant d'exploitations thématiques du catalogue, proposent quelques idées-forces que l'on peut résumer comme suit. Tout d'abord, le profil féminin ou masculin de la divinité propriétaire d'un sanctuaire peut se déduire du sexe des figurines qui lui sont dédiées (comme l'avait pressenti Max Ohnefalsch-Richter). L'identification précise dépend de la présence ou non d'inscriptions. Quand elles sont absentes, la tentation est de pallier ce manque par un recours aux types iconographiques. Or l'A. montre bien que les nombreux types présents dans maints sanctuaires ne renvoient pas nécessairement à des divinités différentes. Au contraire, - et c'est un apport essentiel de la thèse, - il apparaît bien qu'une même déesse peut être la référence de figurines très variées. Toutefois, le statut de ces figurines reste souvent difficile à déterminer (divinité ? prêtresse ? fidèle ?) et l'A. est d'une prudence salutaire sur ce sujet complexe. Quoi qu'il en soit de ce point précis, une même déesse semblerait bien attestée dans une majorité de sanctuaires : sous des appellations locales différentes (Paphia, Golgia, thea, wanassa, despoina, Kupria, etc.), celle en qui les Grecs reconnaissaient leur Aphrodite déploie la large palette de ses prérogatives: protectrice de la sexualité féminine (pourquoi féminine seulement?), de la fécondité des humains et des végétaux, mais aussi du pouvoir et des armes, la "Grande déesse » de Chypre, qui accordait sa bienveillante attention aux différents royaumes des périodes archaïque et classique, sort renforcée de cette analyse. C'est particulièrement évident dans les conclusions que l'A. présente à propos des différents cultes que des inscriptions en grec attribuent à d'autres déesses comme Artémis, Athéna, Héra et Déméter. Il faudrait y voir des "Personifikationen » (p. 258 : les guillemets sont de l'A.) d'aspects particuliers de la Kypris omnipotente. La démonstration est particulièrement appuyée dans le cas d'Athéna, dont les prérogatives bien connues en matière de protection des cités grecques (déesse poliade, guerrière, acropolitaine) en seraient venues à exprimer, de manière singulière dans 
certains lieux comme Idalion et Soloi, ces mêmes aspects qu'aurait assumés (ailleurs? auparavant ?) la déesse générique de l'île.

4 Ce travail très soigné est allé au bout de ce qu'autorisait une interprétation archéologique des données. Il va maintenant s'offrir à un lectorat varié et la réflexion sur le système religieux des royaumes chypriotes pourra se poursuivre sur la base d'un vaste matériel désormais facilement accessible dans un seul ouvrage. D'autres clés de lecture viendront sans doute s'appliquer à ce matériau : la " Grande déesse » aurait-elle toujours le dernier mot dans une perspective davantage anthropologique?

\section{AUTEURS}

VINCIANE PIRENNE-DELFORGE

F.R.S.-FNRS - Université de Liège 